\title{
Vollstreckbarerklärung und Zwangsvollstreckung ausländischer Titel in der Europäischen Union
}

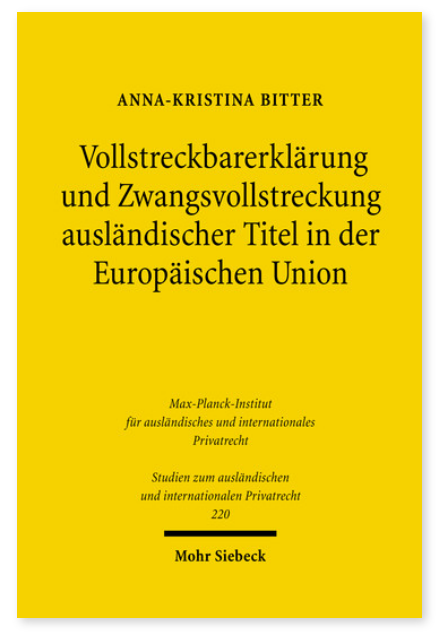

2009. XX, 258 Seiten. StudIPR 220

ISBN 978-3-16-151405-0

DOI 10.1628/978-3-16-151405-0

eBook PDF 64,00€

ISBN 978-3-16-149938-8

fadengeheftete Broschur $64,00 €$
Anna-Kristina Bitter geht im vorliegenden Buch über die Darstellung des Vollstreckbarerklärungsverfahrens der EuGVVO hinaus und beleuchtet Schwierigkeiten bei der tatsächlichen Durchsetzung mitgliedstaatlicher Titel. Gerade die Vollstreckungsorgane der Mitgliedstaaten stehen regelmäßig vor dem Problem, ob sie einen ausländischen Titel wie einen inländischen vollstrecken müssen. Dies führt zu großen praktischen Problemen, wenn das Rechtssystem, aus dem der Tite stammt, keine oder eine gänzlich andere Vollstreckung vorsieht. Die Autorin analysiert das Problem anhand der EuGH Rechtssache WECO/Italian Leather und gibt praktische Lösungsvorschläge. Sie befasst sich auch mit der Frage nach der deutschen Zwangsgewalt bei der Durchsetzung deutscher Titel mit Auslandsbezug. Das wird etwa dann problematisch, wenn eine an sich vertretbare Handlung nicht in Deutschland, sondern im Ausland geschuldet wird.

Anna-Kristina Bitter Geboren 1981; Studium der Rechtswissenschaft in Hamburg; 2008 Promotion; Rechtsreferendarin am Hanseatischen Oberlandesgericht in Hamburg.
Jetzt bestellen:

https://mohrsiebeck.com/buch/vollstreckbarerklaerung-und-zwangsvollstreckung-auslaendischer-titel-in-der-europaeischenunion-9783161514050?no_cache=1

order@mohrsiebeck.com

Telefon: +49 (0)7071-923-17

Telefax: +49 (0)7071-51104 